\title{
UPAYA MENINGKATKAN AKTIVITAS DAN HASIL BELAJAR SEJARAH DENGAN MENGGUNAKAN METODE COOPERATIVE LEARNING TIPE KEPALA BERNOMOR TERSTRUKTUR
}

\author{
Suparno \\ SMA Negeri 1 Punggur Kabupaten Lampung Tengah \\ Email: suparno.suparno19@yahoo.com
}

\begin{abstract}
Latar belakang penelitian ini adalah rendahnya aktivitas belajar siswa yang rendah,siswa kurang termotivasi mengikuti mata pelajaran sejarah, siswa kurang disiplin dalam mengerjakan tugas-tugas yang diberikan oleh guru, begitu juga hasil belajar sejarah yang rendah, dengan demikian peneliti menggunakan metode cooperative learning tipe kepala bernomor terstruktur untuk meningkatkan aktivitas dan hasil belajar sejarah. Penelitian ini menggunakan Penelitian Tindakan Kelas (PTK) dengan subyek penelitian adalah siswa kelas XII IPS 1 semester ganjil pada SMA Negeri 1 Punggur Tahun Pelajaran 2017/2018 pada materi Perjuangan bangsa Indonesia sejak Proklamasi hingga lahirnya Orde. Pada tanggal 21 Agustus - 25 September 2017 yang dilaksanakan dalam 2 siklus dan pada setiap siklus dilaksanakan evaluasi. Dari hasil analisis data diperoleh aktivitas memperhatikan guru menjelaskan dengan indicator $80 \%$ diperoleh $92,1 \%$, aktivitas menyelesaikan masalah dengan indicator $80 \%$ diperoleh $89,1 \%$, aktivitas aktif berdiskusi dengan teman dengan indicator $70 \%$ diperoleh $78,3 \%$, aktivitas memberikan tanggapan dengan indicator $25 \%$ diperoleh $27,4 \%$, dan aktivitas bertanya dengan indicator $15 \%$ diperoleh 18,5\%. Hasil belajar siswa pada siklus I dengan persentase 70,5\% siswa yang tuntas belajar, pada siklus II meningkat menjadi 99\%. Dengan demikian dapat disimpulkan bahwa metode cooperative learning tipe kepala bernomor terstruktur dapat meningkatkan aktivitas dan hasil belajar sejarah siswa kelas XII IPS 1 semester ganjil pada SMA Negeri 1 Punggur Tahun Pelajaran 2017/2018.
\end{abstract}

Kata Kunci: aktivitas Belajar, hasil belajar, sejarah, Cooperative Learning

\begin{abstract}
The background of this study is the low level of student learning activities are low, students are less motivated to follow historical subjects, students are less disciplined in doing the tasks given by the teacher, as well as low historical learning outcomes, thus researchers use cooperative learning type head structured number to increase activity and learning outcomes history. This study uses Classroom Action Research (CAR) with research subjects being XII IPS class 1 odd semester at Punggur 1 Public High School 2017/2018 Academic Year on the Indonesian struggle since the Proclamation until the birth of the Order. On 21 August - 25 September 2017, it was carried out in 2 cycles and in each cycle an evaluation was carried out. From the results of the data analysis, the activity of paying attention to the teacher explained that the indicator $80 \%$ was $92.1 \%$, the activity to solve the problem with the indicator $80 \%$ was $89.1 \%$, the active activity was discussing with a friend with a $70 \%$ indicator, $78.3 \%$, the activity gave a response with a $25 \%$ indicator obtained $27.4 \%$, and asking questions with a $15 \%$ indicator obtained $18.5 \%$. Student learning outcomes in the first cycle with a percentage of $70.5 \%$ of students who completed learning, in the second cycle increased to 99\%. Thus it can be concluded that the cooperative learning method of structured numbered head types can increase the activity and history learning outcomes of XII IPS class students 1 odd semester at Punggur 1 Public High School 2017/2018 Academic Year.
\end{abstract}

Keywords: Learning activities, learning outcomes, history, Cooperative Learning

\section{PENDAHULUAN}

Pendidikan adalah usaha sadar dan terencana untuk membentuk pribadi siswa yang berakhlak mulia cerdas dan terampil.
Upaya yang telah dilakukan pemerintah dalam meningkatkan kualitas pendidikan, diantaranya adalah penyempurnaan kurikulum baik ditingkat dasar, menengah dan 
perguruan tinggi serta penigkatan kwalitas tenaga kependidikan melalui berbagai pelatihan fungsional. Tenaga kependidikan harus lebih giat dalam meningkatkan prestasi belajar siswa dengan cara menciptakan kondisikondisi yang mendorong semangat siswa untuk belajar. Dari sisi siswa diharapkan sungguh sungguh dalam mengikuti proses pembelajaran di kelas.

Dari data observasi pada tanggal 21 Juli 2017 yang di ketahui mengenai kesulitan siswa pada saat belajar sejarah adalah siswa yang mengeluh kurangnya minat belajar mata pelajaran sejarah, kesulitan memahami materi pelajaran sejarah. Keadaan tersebut menyebabkan siswa kurang dapat menyerap materi pelajaran yang diberikan oleh guru secara optimal sehingga hasil belajar tidak sesuai yang dinginkan, dan untuk mengatasi hal tersebut maka perlu dilakukan pemilihan metode yang tepat .

Metode belajar yang diterapkan guru, hendaknya dapat membuat siswa menjadi aktif dan kreatif. Tindakan yang dapat dikategorikan sebagai tindakan aktif dan kreatif yaitu diantaranya dengan metode cooperative learning. Karena metode cooperative learning merupakan suatu metode pembelajaran pemanfaatan kelompok kecil, dimana siswa belajar dan bekerja dalam kelompok-kelompok kecil secara kolaboratif yang anggotanya terdiri dari empat sampai enam orang dengan struktur kelompok yang bersifat heterogen.

Dengan aktivitas belajar siswa yang kurang inilah peneliti termotivasi untuk mengatasi masalah kurangnya minat dan kemauan di atas dan diperlukan penelitian tindakan kelas dengan mengimplementasikan metode cooperative learning dengan tipe kepala bernomor terstruktur, karena metode tipe kepala bernomor terstruktur adalah suatu pendekatan yang dikembangkan untuk melibatkan siswa dalam menelaah materi yang tercakup dalam suatu pelajaran dengan mengecek pemahaman siswa terhadap isi pelajaran. Dan dengan metode ini diharapkan siswa akan lebih aktif dalam belajar yang pada akhirnya dapat meningkatkan hasil belajar.

Metode cooperative learning merupakan metode pembelajaran dengan menggunakan system pengelompokkan/tim kecil, yaitu antara empat sampai enam orang yang mempunyai latar belakang kemampuan akademik, jenis kelamin, ras atau suku yang berbeda atau berbeda (Sanjaya (2003:240)

Langkah langkah dalam menggunakan metode cooperative learning Learning Tipe Kepala Bernomor Terstruktur (Trianto (2007:48)adalah sebagai berikut : (1) Menulis topic pembelajaran di papan tulis 
Menyampaikan tujuan pembelajaran (3) Membagi peserta didik dalam kelompok (setiap kelompok terdiri dari empat sampai lima orang). Membagikan soal yang berisi lima pertanyaan/masalah pada masing-masing kelompok. Masingmasing peserta didik dalam kelompok mengerjakan nomor soal sesuai dengan nomor dada yang dipasang. Selanjutnya, peserta didik dalam kelompok, mendiskusikan jawaban yang benar dan memastikan setiap anggota kelompok dapat mengerjakan/mengetahui jawabannya (4) Memberikan pertanyaan kepada seluruh peserta didik dalam kelas.(5) Guru menunjuk peserta didik yang mengangkat tangan (nomor dada 1 yang belum pernah bicara/mengemukakan pendapat) untuk melaporkan hasil kerjasama dalam kelompok. Peserta didik yang lain memperhatikan dan menanggapi dalam kegiatan diskusi kelompok (6) Menunjuk nomor yang lain sampai seluruh tugas atau soal terlaporkan. (7) Sebagai fasilitator dan motifator guru bertugas membimbing peserta didik melaksanakan diskusi kelas(8) Memberikan penguatan pada hasil diskusi kelas (9) Membimbing peserta didik menyusun kesimpulan.

Aktivitas belajar siswa adalah keterlibatan siswa dalam bentuk sikap,pikiran, perhatian, dan aktivitas dalam kegiatan pembelajaran guna menunjang keberhasilan proses belajar mengajar dan memperoleh manfaat dari kegiatan tersebut, peningkatan aktivitas siswa yaitu meningkatnya jumlah siswa yang bertanya dan menjawab, meningkatnya jumlah siswa yang saling terinteraksi membahas materi pembelajaran.

Aktivitas siswa adalah keterlibatan siswa dalam bentuk sikap, pikiran, perhatian, dan aktivitas dalam kegiatan pembelajaran guna menunjang keberhasilan proses pembelajaran dan memperoleh manfaat dari kegiatan tersebut. ( Kunandar 2008:277)

Menurut Paul D. Diendrich (dalam Hamalik, 2001:172) macam-macam aktivitas belajar dibagi menjadi 8 kelompok:

1. Kegiatan-kegiatan visual. Meliputi membaca, melihat gambar-gambar, mengamati eksperimen, demonstrasi, pameran, dan mengamati orang lain bekerja atau bermain.

2. Kegiatan-kegiatan lisan (oral). Mengemukakan suatu fakta atau prinsip, menghubungkan suatu kejadian, mengajukan pertanyaan, memberi saran, mengemukakan pendapat, wawancara, diskusi dan interupsi.

3. Kegiatan-kegiatan mendengarkan penyajian bahan, mendengarkan percakapan ataudiskusi kelompok, mendengarkan suatu permainan.

4. Kegiatan-kegiatan menulis, Menulis cerita, menulis laporan,memeriksa karangan, bahan-bahan kopi, membuat 
rangkuman, mengerjakan tes dan mengisi angket.

5. Kegiatan-kegiatan menggambar. Menggambar, membuat grafik, chart, diagram peta, dan pola.

6. Kegiatan-kegiatan metrik. Melakukan percobaan, memilih alat-alat, melaksanakan pameran, membuat model, menyelenggarakan permainan, menari, dan berkebun.

7. Kegiatan-kegiatan mental seperti merenungkan, mengingat, memecahkan masalah, menganalisis factor-faktor, melihat, hubungan-hubungan dan membuat keputusan.

8. Kegiatan-kegiatan emosional Meliputi kegiatan minat, membedakan, berani, tenang, dan lain-lain

Hasil belajar adalah penyerapan setinggi-tingginya terhadap apa yang ia pelajari atau apa yang diberikan oleh guru, terutama berupa pengetahuan, Pengertian, aplikasi, analisa, dan evaluasi sehingga siswa tersebut dapat menyeimbangkan prestasi yang dimiliki (Depdikbud dalam Suhartono 1998:13).
Hasil belajar dipengaruhi oleh faktor intern dan ekstern yakni:

1. Faktor intern adalah faktor yang berasal dari dalam diri individu meliputi:

a. Faktor biologi (jasmani) seperti: cacat tubuh dan kesehatan

b. Factor psikologis (kejiwaan) seperti: intelegensi, perhatian minat, bakat, emosi, motivasi dan aktivitas.

2. Factor ekstern adalah factor yang berasal dari luar diri siswa meliputi:

a. Factor keluarga

b. Factor masyarakat

Hasil belajar dapat dilihat dari hasil, ulangan harian (formatif), ulangan harian tengah semester (subsumatif) dan nilai ulangan semester (sumatif). Jadi hasil belajar merupakan puncak dari proses belajar yang dipengaruhi oleh pengalaman dan pada umumnya dinyatakan dalam bentuk angka, dan orang yang telah belajar akan mengalami perubahan baik tingkah laku maupun pengetahuan dan pengalaman.

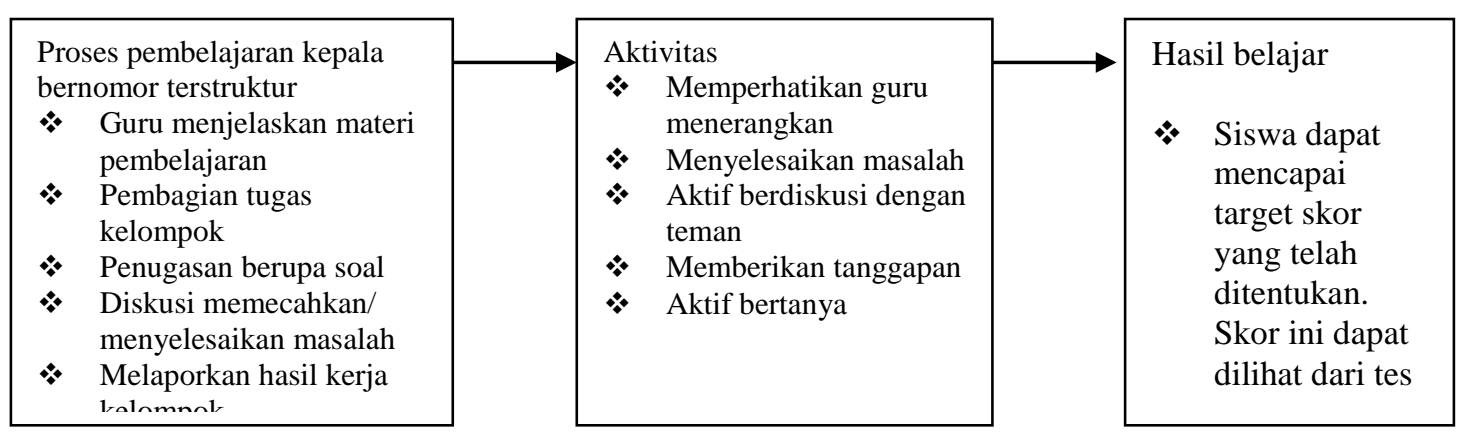

Gambar 1. Keterkaitan antara metode cooperative learning tipa kepala bernomor terstruktur dengan aktivitas dan hasil belajar 


\section{METODE PENELITIAN}

Penelitian ini merupakan penelitian tindakan kelas, dengan pendeketan deskriptip.

Metode deskriptip ini memberikan gambaran suatu upaya perbaikan mutu proses pembelajaran dalam bentuk kegiatan penelitian tindakan kelas (PTK). Penelitian ini dilaksankan pada siswa kelas XII IPS 1 semester ganjil Tahun Pelajaran 2017/2018 SMA Negeri 1 Punggur Kab. Lampung Tengah, dengan ruang lingkup materi Perjuangan Bangsa Indonesia Sejak Proklamasi Hingga Lahirnya Orde Baru.

Upaya pemechan masalah dalam penelitian ini difokuskan untuk memperbaiki mutu pembelajaran sejarah di kelas terutama peningkatan aktivitas belajar dan hasil bekajar sejarah dengan menggunakan metode pembelajaran Coopperative Learning Tipe Kepala Bernomor Terstruktur. .

Metode Penelitian Tindakan Kelas (PTK) menggunakan model PTK yang dikemukakan Arikunto (2006:16) yaitu : 1)Perencanaan, 2)Pelaksanaan, 3) Pengamatan, 4) Refleksi.

Penelitian ini diklaksanakan dua siklus, pada siklus I dilakukan kegiatan yang dimulai dari perencanaan, pelaksanaan tindakan, pengamatan dan refleksi. Dari kedua siklus tersebut diajukan suatu rekomendasi terkait dengan pengambilan keputusan untuk penigkatan aktifitas belajar dan hasil belajar sejarah menggunakan model pembelajaran Coopperative Learning Tipe Kepala Bernomor Terstruktur.

\section{Indikator Keberhasilan}

Indikator keberhasilan

Aktifitas pembelajaran pada siklus 1 yaitu : 1) Peningkatan memperhatikan guru menerangkan, 2) Ada peningkatan kemapuan menyelesaikan masalah, 3)Aktif berdiskusi, 4)Kemampuan memberikan tanggapan dan peningkatan minat bertanya. Sedangkan hasil belajar pencapian nilai KKM 60. Apabila target ini belum tercapai pada siklus 1maka akan dilakukan perbaikan pembelajaran pada siklus II. Diharapkan pada siklus II indikator keberhasilan penerapan pembelajaran kooperatif learning dapat tercapai.

\section{Analisis Data}

Analisis Data yang yang digunakan dalam penelitian ini adalah menggunakan metode deskriptif. Data yang disajikan dalam bentuk tabel tabel dan menggunakan ukuran ukuran statistik yang sederhana, seperti ratarata, persentase dan gambaran deskriptif naratif dari proses pembelajaran yang berlangsung $\mathrm{di}$ sekolah. Sumber data yang dianalisis berasal dari lembar observasi angket dan tes. 


\section{HASIL PENELITIAN DAN PEMBAHASAN}

Peningkatan aktivitas siswa.

Aktifitas belajar menunjukkan bahwa 5(lima) aktivitas mencapai target yaitu memperhatikan guru menjelaskan 92,1\% dengan target $80 \%$ meningkat $12,1 \%$, menyelesaikan masalah $89,1 \%$ dengan target $80 \%$ meningkat 9,1\%, aktif berdiskusi dengan teman $78,3 \%$ dengan target $70 \%$ meningkat $8,3 \%$, memberikan tanggapan 27,4\% dengan target 25\% meningkat $2,4 \%$ dan aktivitas bertanya $18,5 \%$ dengan target 15\% meningkat $3,5 \%$, dari kelima aktivitas sudah mencapai target disebabkan pada saat proses pembelajaran siklus II siswa sudah mulai memiliki rasa tanggungjawab terhadap dirinya dan kelompok sehingga membawa dampak yang positif terhadap aktivitas siswa dan bersifat menunjang siswa untuk memahami materi yang diajarkan oleh guru.

Aktivitas yang mengalami peningkatan paling besar adalah memperhatikan guru menjelaskan, menyelesaikan masalah, dan aktif berdiskusi dengan teman, siswa yang memiliki atau berkemampuan lebih prestasi belajarnya bisa membantu siswa yang berkemampuan belajar kurang. Pembelajaran cooperative menekankan adanya tugas-tugas kelompok yang memungkinkan siswa belajar bersama teman kelompoknya dalam penguasaan dan kemampuan memahami materi pelajaran. Kondisi ini memungkinkan siswa tergantung secara positif antara siswa yang satu dengan yang lain dalam mempelajari dan menyelesaikan tugas yang diberikan oleh guru selain itu adanya aktivitas guru yang sudah baik dan berpengalaman dalam pembelajaran yang juga membantu dalam keberhasilan dari kegiatan belajar mengajar.

Dari kelima aktivitas dapat mencapai peningkatan signifikan pada siklus II karena suasana belajar cooperative memungkinkan terjadinya interaksi belajar dalam kelompok yang bersifat langsung dan terbuka dalam mendiskusikan materi atau tugas yang diberikan guru. Dalam hal ini siswa bisa lebih saling memberi dan menerima masukan ide, saran, dan kritik dari temannya secara positif dan terbuka. Sehingga semua aktivitas dapat mencapai target.

Tabel 1. Aktivitas Siswa dalam Metode Cooperative Learning Tipe Kepala Bernomor Terstruktur Siklus I

\begin{tabular}{|c|c|c|c|c|c|c|c|}
\hline \multirow{2}{*}{ No. } & \multirow{2}{*}{ Aktivitas } & \multicolumn{3}{|c|}{ Pertemuan } & \multirow{2}{*}{ Rata-rata } & \multirow{2}{*}{ Indicator } & \multirow[b]{2}{*}{ Ket. } \\
\hline & & 1 & 2 & 3 & & & \\
\hline 1 & $\begin{array}{l}\text { Memperhatikan } \\
\text { guru menjelaskan }\end{array}$ & $94,1 \%$ & $88,2 \%$ & $94,1 \%$ & $92,1 \%$ & $80 \%$ & $\mathrm{~T}$ \\
\hline 2 & $\begin{array}{l}\text { Menyelesaikan } \\
\text { masalah }\end{array}$ & $85,2 \%$ & $88,2 \%$ & $94,1 \%$ & $89,1 \%$ & $80 \%$ & $T$ \\
\hline
\end{tabular}




\begin{tabular}{|l|l|c|c|c|c|c|c|}
\hline 3 & $\begin{array}{l}\text { Aktif berdiskusi } \\
\text { dengan teman }\end{array}$ & $70,5 \%$ & $76,4 \%$ & $88,2 \%$ & $78,3 \%$ & $70 \%$ & $\mathrm{~T}$ \\
\hline 4 & $\begin{array}{l}\text { Memberikan } \\
\text { tanggapan }\end{array}$ & $26,4 \%$ & $26,4 \%$ & $29,4 \%$ & $27,4 \%$ & $25 \%$ & $\mathrm{~T}$ \\
\hline 5 & Bertanya & $17,6 \%$ & $20,5 \%$ & $17,5 \%$ & $18,5 \%$ & $15 \%$ & $\mathrm{~T}$ \\
\hline
\end{tabular}

Tabel 2. Rata-rata Persentase Aktivitas Siswa dengan Menggunakan Metode Cooperative Learning Tipe Kepala Bernomor Terstruktur Siklus I dan Siklus II

\begin{tabular}{|c|l|c|c|c|c|c|}
\hline No. & \multicolumn{1}{|c|}{ Aktivitas } & Indicator & Siklus I & Siklus II & $\begin{array}{c}\text { Tercapai/ } \\
\text { tidak tercapai }\end{array}$ & Peningkatan \\
\hline 1. & $\begin{array}{l}\text { Memperhatikan guru } \\
\text { menjelaskan }\end{array}$ & $80 \%$ & $86,2 \%$ & $92,1 \%$ & $\mathrm{~T}$ & $5,9 \%$ \\
\hline 2. & $\begin{array}{l}\text { Menyelesaikan } \\
\text { masalah }\end{array}$ & $80 \%$ & $84,2 \%$ & $89,1 \%$ & $\mathrm{~T}$ & $4,9 \%$ \\
\hline 3. & $\begin{array}{l}\text { Aktif berdiskusi } \\
\text { dengan teman }\end{array}$ & $70 \%$ & $62,7 \%$ & $78,3 \%$ & $\mathrm{~T}$ & $15,6 \%$ \\
\hline 4. & $\begin{array}{l}\text { Memberikan } \\
\text { tanggapan }\end{array}$ & $25 \%$ & $12,7 \%$ & $27,4 \%$ & $\mathrm{~T}$ & $14,7 \%$ \\
\hline 5. & Bertanya & $15 \%$ & $10,7 \%$ & $18,5 \%$ & $\mathrm{~T}$ & $7,8 \%$ \\
\hline
\end{tabular}

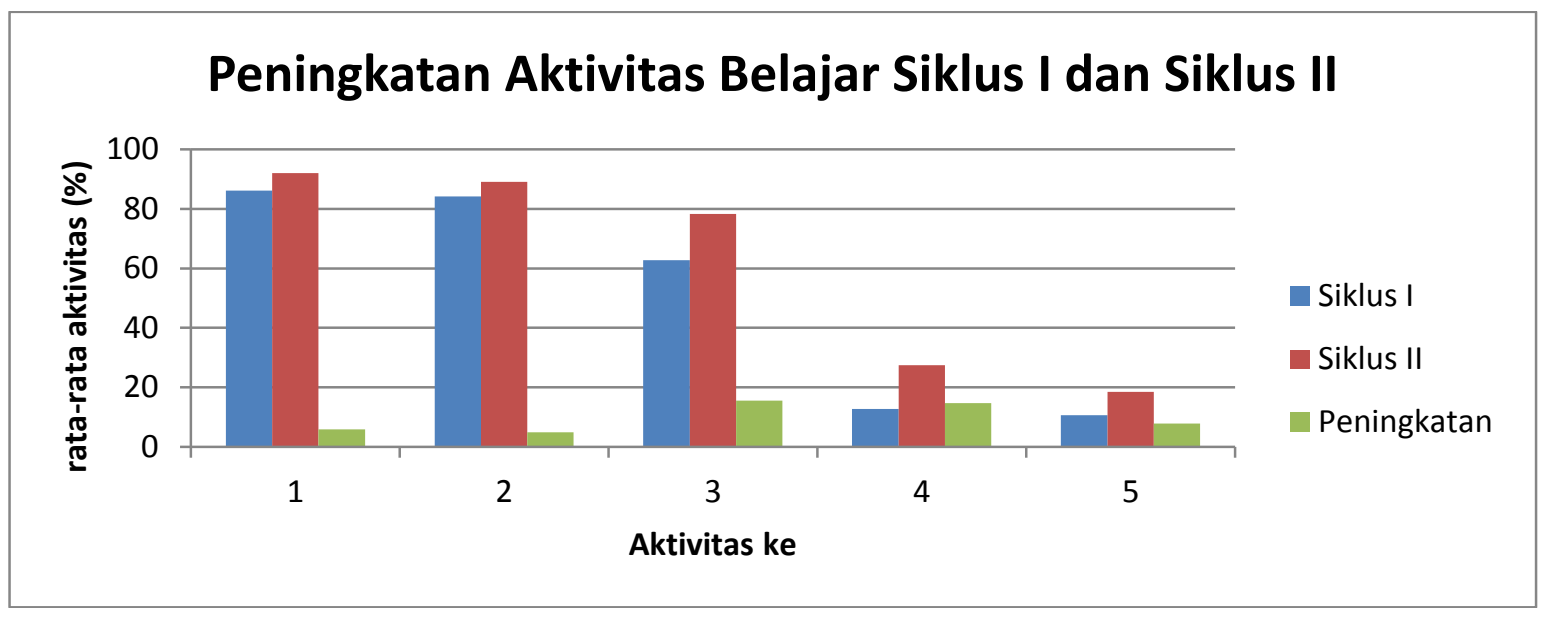

Gambar 1. Diagram Peningkatan Aktivitas Belajar Sisklus I dan Siklus II Dari diagram diatas terlihat bahwa aktivitas belajar siswa di sikluls II lebih baik pada siklus I.

Peningkatan hasil belajar siswa pada saat pembelajaran dengan menggunakan metode cooperative learning tipe kepala bernomor terstruktur

Tabel 3. Hasil Belajar Tes Siklus I dan Siklus II

\begin{tabular}{|c|l|c|c|c|c|}
\hline \multirow{2}{*}{ No. } & \multirow{2}{*}{ Kategori } & \multirow{2}{*}{ Nilai } & \multicolumn{2}{|c|}{ Persentase } & \multirow{2}{*}{ Target } \\
\cline { 4 - 5 } & & & Siklus I & Siklus II & \\
\hline 1. & Tuntas & $\geq 60$ & 14 & $20(100 \%)$ & $75 \%$ \\
2. & Tidak tuntas & $<60$ & $(70,5 \%)$ & $0 \%$ & \\
& & & $6(29,5 \%)$ & & \\
\hline \multicolumn{2}{|c|}{ Jumlah } & & $100 \%$ & $100 \%$ & \\
\hline & & & & \\
\hline
\end{tabular}




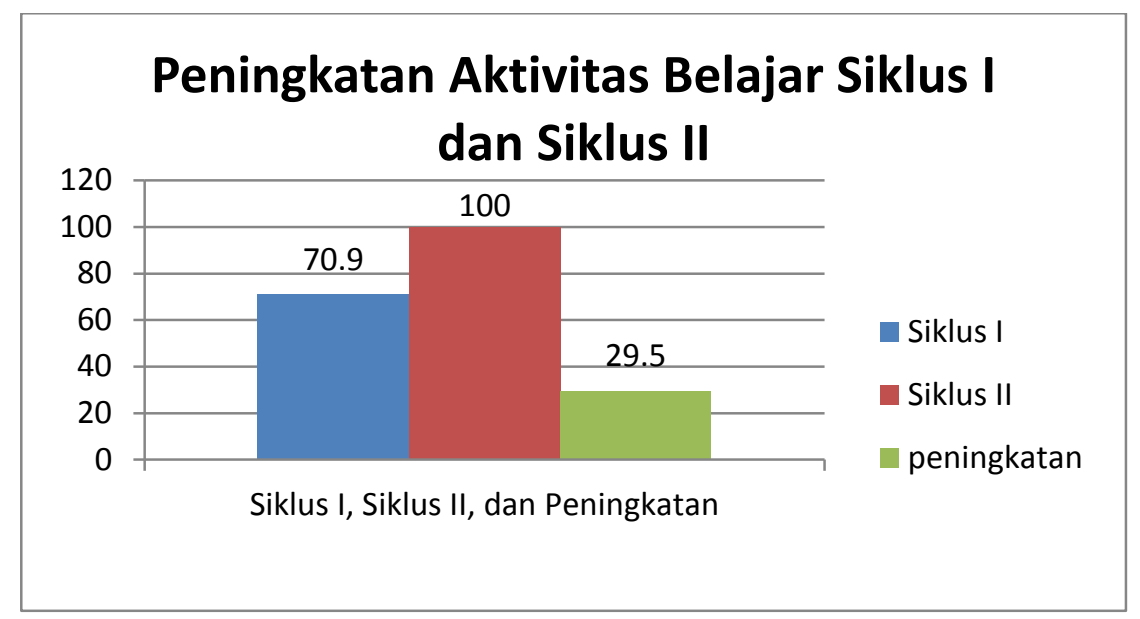

Gambar 2. Diagram Peningkatan Hasil Belajar Siklus I dan II

Data diagram diatas menunjukkan bahwa hasil belajar siswa yang mencapai ketuntasan hasil belajar pada siklus $I \geq 60$ sebesar $70,5 \%$ atau 14 siswa dan pembelajaran pada siklus II mengalami peningkatan yaitu $100 \%$ atau 20 siswa dan data hasil belajar dari siklus I ke siklus II mengalami peningkatan, hal ini disebabkan karena proses pembelajaran pada siklus II telah dilakukan upaya memperbaiki pencapaian target indicator aktivitas, dan hasil belajar yang belum tercapai pada siklus I setelah melakukan tes akhir siklus pada siklus I.

Upaya-upaya yang dilakukan antara lain memberikan motivasi kepada siswa dengan cara memberi penghargaan kepada individu berupa ucapan selamat dan penghargaan dengan pemberian hadiah berupa kado kepada kelompok. Pada akhir siklus I, jika siswa mengikuti proses pembelajaran dengan baik dan melakukan 5 aktivitas dengan aktif terutama aktivitas memperhatikan guru menjelaskan, menyelesaikan masalah, aktif berdiskusi, memberikan tanggapan dan mengajukan pertanyaan yang belum dipahami. Menertibkan suasana kelas pada saat metode cooperative learning tipe kepala bernomor terstruktur dimulai, merevisi anggota yang aktif, melakukan pendekatan individual, membantu dan memberikan pengarahan kepada siswa yang belum paham terhadap materi atau soal latihan yang dianggap sulit. Dengan adanya tes akhir pada siklus I dan perbaikan proses pembelajaran pada siklus II maka hasil pembelajaran pada siklus II dapat ditingkatkan.

Data hasil belajar siklus I $(70,5 \%)$ ke siklus II (100\%) mengalami peningkatan, hal ini menunjukkan bahwa hasil belajar sejarah siswa kelas XII IPS 1 SMA Negeri 1 Punggur mencapai ketuntasan dalam pembelajaran. Peningkatan ketuntasan hasil belajar sejarah merupakan 
dampak dari pembelajaran menggunakan metode cooperative learning tipe kepala bernomor terstruktur. Siswa yang tuntas belajar memiliki aktivitas belajar baik, aktivitas belajar tinggi yaitu melakukan aktivitas memperhatikan guru menjelaskan, menyelesaikan masalah, aktif berdiskusi dengan teman, memberikan tanggapan dan bertanya. Aktivitas tersebut merupakan rangkaian tahapan dalam metode cooperative learning tipe kepala bernomor terstruktur yang bertujuan untuk memecahkan masalah dan meningkatkan kinerja siswa dalam tugas-tugas akademik. Selain itu, adanya struktur penghargaan berupa ucapan selamat dan pemberian hadiah berupa kado yang dapat meningkatkan penelitian siswa pada proses pembelajaran yang berhubungan dengan hasil belajar. Hasil penelitian ini juga mendukung penelitian sebelumnya yang dilakukan oleh Erma (2008) yang menunjukkan dengan pembelajaran dengan metode cooperative learning tipe kepala bernomor terstruktur dapat meningkatkan saktivitas dan hasil belajar siswa.

\section{KESIMPULAN DAN SARAN Kesimpulan} Berdasarkan hasil Penelitian Tindakan Kelas dan pembahasan yang telah dilakukan, maka dapat diambil kesimpulan pembelajaran dengan menggunakan metode cooperative learning tipe kepala bernomor terstruktur sebagai berikut:

1. Metode cooperative learning tipe kepala bernomor terstruktur dapat meningkatkan aktivitas siswa dalam pembelajaran siswa kelas XII IPS 1 SMA Negeri 1 Punggur semester ganjil tahun pelajaran 2017/2018.

2. Metode cooperative learning tipe kepala bernomor terstruktur dapat meningkatkan hasil belajar siswa kelas XII IPS 1 SMA Negeri 1 Punggur semester ganjil tahun pelajaran 2017/2018.

\section{Saran}

Berdasarkan kesimpulan dalam penelitian ini, maka dapat dikemukakan saran sebagai berikut:

1. Agar hasil belajar sejarah lebih maksimal, maka disarankan bagi guru untuk menggunakan metode yang tepat dalam proses pembelajaran sesuai dengan materi, agar siswa tidak merasa jenuh seperti menggunakan metode cooperative learning tipe kepala bernomor terstruktur, dengan memperhatikan hal-hal sebagai berikut:

a. Pemberian kartu bernomor tiap siswa yang berwarna-warni agar terlihat menarik. 
b. Membuat

nama-nama

kelompok untuk lebih bervariasi, misalnya dengan nama-nama istilah seperti contohnya kelompok I dengan nama anggur dan lain-lain.

c. Untuk setiap nomor yang dipanggil untuk melaporkan hasil kerjasama kelompok, bilang siap, supaya lebih bersemangat.

2. Bagi siswa SMA Negeri 1 Punggur terutama kelas XII IPS 1 kiranya dapat melatih diri dengan mengerjakan soal-soal latihan dan hendaknya jangan malu dan rendah diri pada saat pembelajaran berlangsung untuk bertanya dan memberi tanggapan serta untuk lebih aktif dalam proses pembelajaran menggunakan metode cooperative learning tipe kepala bernomor terstruktur.

\section{DAFTAR PUSTAKA}

Arikunto, Suharsimi. (2003). DasarDasar Evaluasi Pendidikan. Jakarta. Bumi Aksara

Arikunto, Suharsimi. (2006). Penelitian Tindakan Kelas. Jakarta. Bumi Aksara

Arikunto, Suharsimi. (2006). Prosedur Penelitian Pendekatan Suatu Prakter. Jakarta. Rineka Cipta

Chotimah, Husnul. (2009). Strategi Pembelajaran. Jakarta. Rineka Cipta
Chotimah, Husnul (2006). http/learning. withmeblogspot.co m/2006/09/Pembelajaran. html. diakses 5 September 2007.

Isjoni. (2007). Cooperative Learning: Mengembangkan Kemampuan Belajar Berkelompok. Bandung. Alfabeta.

Juhri. (2006). landasan dan Wawasan Pendidikan. Universitas Muhammadiyah Metro. Lembaga Penelitian.

Kunandar. (2008). Langkah Mudah Penelitian Tindakan Kelas Sebagai Pengembangan Profesi Guru. Jakarta. Grafindo.

Lie, Anita. (2003). Upaya Meningkatkan Aktivitas dan Hasil Belajar Menggunakan Metode Cooperative Learning Tipe Numbered Heads Together Siswa Kelas XI MAN 2 Metro Semester Ganjil Tahun 2007/2008.

Noor, Marzuki. (2003). Pedoman Penulisan Karya Ilmiah. Metro. Universitas Muhammadiyah Metro.

Nurkancana, Wayan. (1986). Evaluasi Pendidikan. Jakarta. Usaha Nasional

Sanjaya, Wina. (2003). Strategi Pembelajaran. Jakarta. Rineka Cipta.

Sholihatin, Etin. (2005). Cooperative Learning. Jakarta. Bumi Aksara

Trianto. (2007). Model-model Pembelajaran Inofatif Berorientasi Kontruktivistik. Surabaya. Prestasi. Pustaka 